\title{
Characteristics of the Austenitic Steels Used in the LHC Main Dipoles
}

\author{
C. Lanza and D. Perini
}

\begin{abstract}
The LHC dipole structure is assembled using austenitic steel collars and austenitic steel end-laminations. The collars will be fine-blanked starting from 11000 tons of steel; the end-laminations require 1700 tons of steel.

The procurement of the austenitic steels was divided in two phases: first, we qualified different grades from different producers, and then, we made the call for tender, adjudicated the contract and started the series production. The first part of this paper summarizes the results of the first qualification phase when extensive checks and measurements were carried out on five different grades.

The second part describes the approach used to control the series production and the results obtained. At the time of writing about $19 \%$ of the steel for collars and end-laminations has been manufactured and delivered.
\end{abstract}

Index Terms-Collars, steel selection.

\section{INTRODUCTION}

A FTER the decision of making the LHC main dipole collars using austenitic steel instead of aluminum [1] we launched a campaign for the qualification and test of possible grades suitable for this application. In the mean while we also qualified a grade for the end laminations.

The market survey and qualification procedure lasted approximately six months. After this phase we launched the call for tenders and we concluded a contract with one producer of the steel for collars (Nippon Steel Corporation) and one of the steel for nonmagnetic yoke laminations (Kawasaki Steel Corporation).

The steel for collars represents a critical item for the correct performance of the LHC dipoles. The LHC machine requires the use of about 1250 dipoles implying the production of 11000 tons of austenitic steel. The collars are important in the definition of the dipole field quality. Their dimensions must be extremely precise (tolerances of $\pm 20 \mu \mathrm{m}$ in critical positions) obtained by means of a fine-blanking technique (precise punching) and reproducible all along the production. The collars are locally heavily stressed and work at $1.9 \mathrm{~K}$. These facts call for high performance and reproducibility of the mechanical properties. The relative magnetic permeability must be as close as possible to 1.0 and constant along the production in order not to impair the field quality.

The steel for nonmagnetic end-yoke laminations is less critical since these pieces are not heavily stressed. The LHC machine requires the production of 1700 tons of this material. For

Manuscript received September 24, 2001.

The authors are with the Main Magnet and superconductor Group, LHC division, CERN, 1221 Geneva 23, Switzerland (e-mails: \{Cristiano.Lanza; Diego.Perini\}@cern.ch).

Publisher Item Identifier S 1051-8223(02)04172-6. this steel as well we need reproducible properties and constant dimensions of the fine-blanked parts during the whole production.

The most important feature required for this grade is its thermal contraction. It is important to have a thermal contraction as close as possible to that of the soft iron used for the yoke laminations in the straight part $\left(\sim 2 \cdot 10^{-3}\right.$ between room temperature and $1.9 \mathrm{~K}$ ).

\section{QuALIFICATION OUTLINE}

We purchased steel in various grades from different producers in order to manufacture collars for the dipole prototypes. The criteria for choosing the supplier were the availability of a grade fulfilling our technical requirements in the steel producer catalogue and his interest and good willingness to deliver material in time to respect the construction planning of our dipole magnets. The idea behind the qualification procedure was to test the complete chain from the steel production to the magnet manufacturing. We measured the steel features and behavior, we fine-blanked several thousands of collars and assembled at least one full size prototype with each given grade.

The characteristics that were systematically measured for each steel grade are the following:

1) Magnetic permeability at $4.2 \mathrm{~K}$ and $1.9 \mathrm{~K}$,

2) Thermal contraction between room temperature and operational temperature $(1.9 \mathrm{~K})$,

3) Mechanical properties at room temperature and at $77 \mathrm{~K}$,

4) Metallurgical features (grain size, inclusions, ferrite content etc.).

With the collaboration of the fine-blankers we tried as well to estimate the fine-blanking suitability of the different grades. We considered the precision and reproducibility of the collars, the wear of the tooling, the flatness of the collars and the quality of the cut. It is difficult or impossible to quantify all these parameters after the cutting of few thousands of collars. In principle we should have produced more collars to get better statistics. Therefore the judgment is mainly based on the experience and the know-how of the fine-blankers. The experience gained with the series production tells us that the preliminary evaluation done for a grade at the beginning is almost confirmed or achieved even better performances after the fine-blanking of several thousand of pieces when all the cutting parameters are optimized.

\section{QUALIFICATION DATA}

During the market survey phase we were able to pre-select and test five different grades of steel as shown in the following Table I. 
TABLE I

GRADES TESTED

\begin{tabular}{|c|c|}
\hline Grade & Producer \\
\hline $13 \mathrm{AM} 19^{\circ}$ & Sandvik \\
\hline $20-7 \mathrm{MN}^{3}$ & Ugine \\
\hline rus $130 \mathrm{~S}^{\circ}$ & Nippon \\
\hline Hytorm 200 mod. & Avesta Shellield \\
\hline KHMN² & Kawลsabj \\
\hline
\end{tabular}

TABLE II

Nominal Chemical Composition (\% OF TOTAL Weight)

\begin{tabular}{|c|c|c|c|c|c|c|c|c|c|}
\hline Grade & C & Si & Mn & P & 5 & $\mathrm{Cr}$ & $N_{0}$ & $\mathbf{N i}$ & N \\
\hline 13РM19 & 8.11 & 6.05 & 84 & का & 6.01 & $18 \pi$ & 0.36 & 72 & 0.26 \\
\hline $20-7 \mathrm{MN}$ & tos & 0.22 & 212 & 400 & t.0002 & $a$ & asat & 4.86 & 0.4 \\
\hline YUS $130 \mathrm{~S}$ & 609 & 0.4 & ta. 7 & $\sin$ & $\cos$ & s & at & 48 & 0.28 \\
\hline Hytorm $200 \mathrm{mod}$. & 0.1 & 0.25 & 81 & 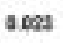 & 0.091 & 18.4 & Q.14 & 79 & 4.25 \\
\hline KHMN & 0.1 & 0.4 & a & 0.002 & coss & 6.7 & e. & ans & a.t \\
\hline
\end{tabular}

TABLE III

Relative Magnetic Permeability $\mu_{r}$ (ACCuRACy BetTer Than 1\%) AT DifFERENT TEMPERATURE AND DifFERENT MAGNETIC FIELD VALUES

\begin{tabular}{lcccc}
\hline \multicolumn{1}{c}{ Grade } & $\mu_{r}$ at $4.2 \mathrm{~K}$ & $\mu_{r}$ at $4.2 \mathrm{~K}$ & $\mu_{r}$ at $1.8 \mathrm{~K}$ & $\mu_{r}$ at $1.8 \mathrm{~K}$ \\
\hline \multirow{3}{*}{ 13FM19 } & $\mathrm{B}=0.1 \mathrm{~T}$ & $\mathrm{~B}=3 \mathrm{~T}$ & $\mathrm{~B}=0.1 \mathrm{~T}$ & $\mathrm{~B}=3 \mathrm{~T}$ \\
$20-7 \mathrm{MN}$ & 1.003 & 1.0028 & 1.0029 & 1.0028 \\
YUS 130 S & 1.0021 & 1.0019 & 1.0021 & 1.002 \\
Hyorm 200 mod. & 1.0022 & 1.0019 & 1.0019 & 1.0019 \\
KHMN & 1.0026 & 1.0026 & 1.0025 & 1.0025 \\
\hline
\end{tabular}

TABLE IV

Thermal Contraction $(\Delta L / L)$ BETwEen RoOM TEMPERATURE AND $1.9 \mathrm{~K}$

\begin{tabular}{lc}
\hline \multicolumn{1}{c}{ Grade } & Thermal contraction Ail \\
\hline $13 F M 19$ & $2.7 \cdot 10^{-4}$ \\
$20-7$ MN & $2.7 \cdot 10^{-4}$ \\
YUS $130 \mathrm{~S}$ & $2.6 \cdot 10^{4}$ \\
Hytom 200 mod. & $2.7 \cdot 10^{4}$ \\
KHMN & $1.8+10^{4}$ \\
\hline
\end{tabular}

The chemical composition of each grade is given in Table II.

Concerning the magnetic permeability, the specified value defined in the technical specification is $\mu_{r} \leq 1.003$ at $1.9 \mathrm{~K}$ with a magnetic field excitation of $H \geq 8 \times 10^{4} \mathrm{~A} / \mathrm{m}\left(\mu_{0} H \sim 0.1 \mathrm{~T}\right)$ for the collar grade and $\mu_{r} \leq 1.005$ in the same conditions for the end-yoke lamination grade. Table III shows the obtained results under different magnetic field values.

In the technical specification the required value for the thermal contraction between room temperature and $1.9 \mathrm{~K}$ is $2.2 \cdot 10^{-3} \leq \Delta l / l \leq 2.6 \cdot 10^{-3}$ for the collar grade and $1.6 \cdot 10^{-3} \leq \Delta l / l \leq 2.2 \cdot 10^{-3}$ for the end-yoke lamination grade. The Table IV shows the obtained results.

The measurements were performed with an accuracy of \pm 0.1 . $10^{-3}$. A more accurate device $\left( \pm 0.05 \cdot 10^{-3}\right)$ based on laser measurements through a window in a cryostat has been devel-
TABLE $\mathrm{V}$

SPECIFIED VALUES

\begin{tabular}{|c|c|c|c|}
\hline & Characioriate & 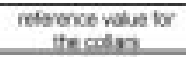 & 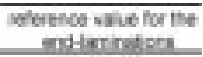 \\
\hline \multirow[t]{4}{*}{ Foom temperature } & Neld viergeth कy & 400600 ure & $250-250 \mathrm{NT}$ \\
\hline & Tomile neregh os & Treses ure & neseso ups \\
\hline & Diongition $\mathrm{A}$. & 2006 & $249 \mathrm{x}$ \\
\hline & Martrean ias GTeO & $=160$ & $=900$ \\
\hline \multirow[t]{2}{*}{ At $77 \mathrm{~K}$} & 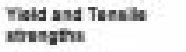 & $\begin{array}{l}\text { Mperior so the roon } \\
\text { temperzare oneen }\end{array}$ & 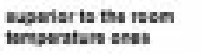 \\
\hline & Dorgition Ay & 2100 & $298 x$ \\
\hline
\end{tabular}

TABLE VI

MeChanical PROPERTIES AT ROOM TEMPERATURE

\begin{tabular}{|c|c|c|c|c|c|}
\hline Grade & ${ }_{0.2}$ [MPa] & ${ }^{\circ}$ [NPa] & $A_{5}$ & $E[\mathrm{GPa} \mid$ & Fas 9/750 \\
\hline 13 PM19 & 440 & 800 & $52 \pi$ & 200 & 260 \\
\hline $20-7 \mathrm{MN}$ & 450 & 795 & $50 \%$ & 183 & 234 \\
\hline YUS $130 \mathrm{~S}$ & 45 & 785 & $50 \%$ & 194 & 280 \\
\hline Hytorm 200 mod. & 390 & 763 & $54 \%$ & 168 & $2 \pi 7$ \\
\hline KHMN & 320 & 690 & $67 \%$ & 188 & 220 \\
\hline
\end{tabular}

TABLE VII

Mechanical Properties at $77 \mathrm{~K}$

\begin{tabular}{|c|c|c|c|}
\hline Grade & $D_{a .2}[\mathrm{MPa}]$ & $\sigma_{R}[\mathrm{MPa}]$ & $A_{s}$ \\
\hline 13PM19 & 1113 & 1634 & $66 \%$ \\
\hline $20-7 \mathrm{MN}$ & 1136 & 1650 & $46 \%$ \\
\hline Yus $130 \mathrm{~S}$ & 1023 & 1595 & $48 \%$ \\
\hline Hyform $200 \mathrm{mod}$ & 936 & 1533 & $65 \%$ \\
\hline KHMN & 1050 & 1600 & $50 \%$ \\
\hline
\end{tabular}

TABLE VIII

Metallurgical ANALYsis

\begin{tabular}{lccc}
\hline \multicolumn{1}{c}{ Grade } & grain size & residual ferrite & $\max$ \\
\hline $13 F M 19$ & $8-9$ & low & $1 \%$ \\
$20-7$ MN & $7-8$ & low & $1 \%$ \\
YUS 130 S & 6 & no residual ferrite & \\
Hyform 200 mod. & $7-8$ & low & 0.002 \\
KHMN & 6 & no residual ferrite & \\
\hline
\end{tabular}

oped to follow the series production but we did not repeat the measurements for the nonselected grades.

The specified values for the mechanical properties are the following (Table V).

The measured values are reported in the following Tables VI and VII. There is a very good reproducibility from sample to sample (less than $5 \%$ of difference).

The specification (for both collars and end-yoke laminations) states that, at a microstructural observation, the structure have to be fully austenitic and with a maximum grain size 4 , according to ASTM E112-83. Table VIII shows the results of the measurements.

Concerning the fine-blanking suitability, the judgment from the fine- blankers based on a limited number of tests can be summarized in the following Table IX. 
TABLE IX

COLLARS FINE-BLANKING SUITABILITY

\begin{tabular}{|c|c|}
\hline Hylorm $200 \mathrm{mod}$ : & $\begin{array}{l}\text { good fistess of fhe colsrs (footh from cols and sheets) } \\
\text { very good cul } \\
\text { relutvely low tooling wear }\end{array}$ \\
\hline YUS $130 \mathrm{~S}$ : & 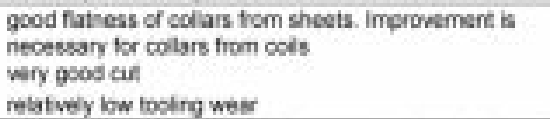 \\
\hline $20-7-\mathrm{MN}$ : & 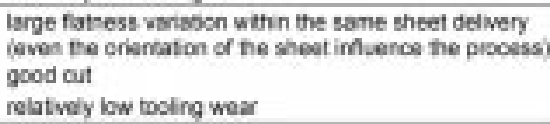 \\
\hline 13АM19: & 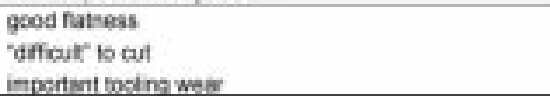 \\
\hline
\end{tabular}

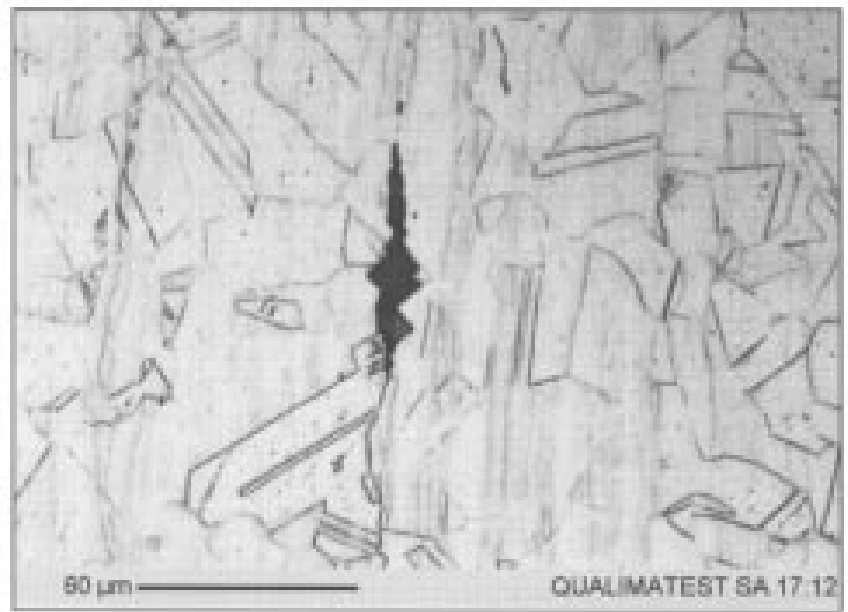

Fig. 1. Sample with the ferrite rate of $1 \%$ (the dark area).

\section{QUALIFICATION CONCLUSIONS}

At the end of the qualification procedure we can conclude that all the selected grades are of good quality. Some weak points can be improved with the experience that will be gained producing a large amount of material.

The 13RM19, 20-7 MN, YUS130S and Hyform 200 mod. are good grades for the collar production. The KHMN is a good grade for the nonmagnetic end-yoke laminations.

The grade YUS130S [3] for the collars and KHMN [5] for the end-yoke laminations were finally chosen, after a call for tender, according to the best commercial offer received.

The remaining overview of this paper is mainly focalized on the steel for the collars.

\section{About the Magnetic Permeability}

As explained in the introduction one of the most important parameters to monitor for collars materials is the magnetic permeability of these grades. During the measurements one sample of the grade Hyform 200 mod. was found out of tolerance with a magnetic permeability of 1.0038 at $0.1 \mathrm{~T}, 1.8 \mathrm{~K}$ and 1.0026 at $3 \mathrm{~T}, 1.8 \mathrm{~K}$. In order to understand the problem an analysis of the ferrite rate was made. The sample was cut every $0.5 \mathrm{~mm}$ along the width. The maximum rate of ferrite (1\%) was found just under the surface (see Fig. 1). This behavior can explain the increasing of the magnetic permeability in this sample.

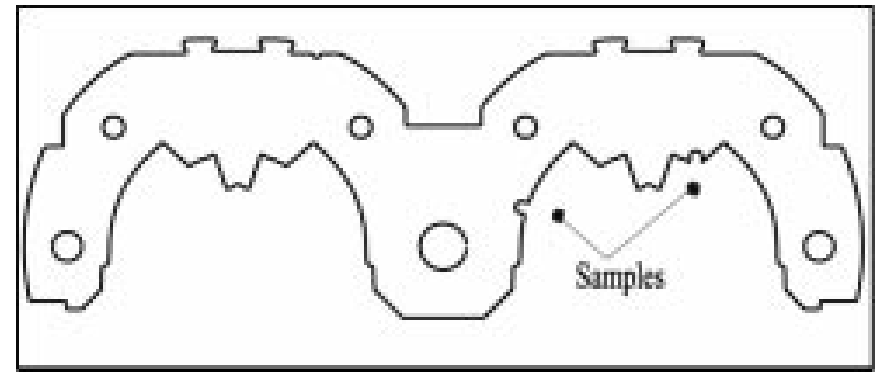

Fig. 2. Collar shape (male figure) with indicated where samples for magnetic permeability measurements are taken.

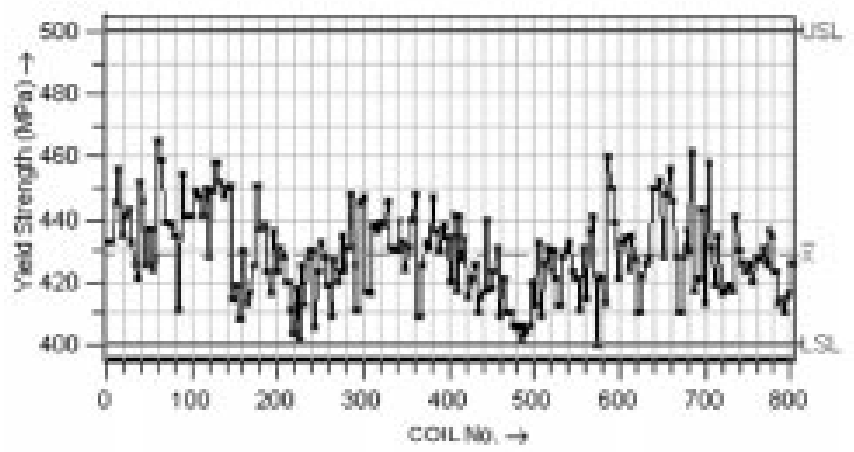

Fig. 3. Yield Strength, as a function of sequence of the coils; LSL and USL are respectively the lower and the upper specification limit.

This grade was specially developed for this application and the sample belongs to the very first melt. The producer confirmed that some parameters in the process were found to be inappropriate during the test melt and we are convinced that the implemented corrections will avoid any problem in the future.

To investigate the effect of the fine-blanking on the magnetic permeability of the collar edge, two samples (as shown in Fig. 2.) were cut and measured at $4.2 \mathrm{~K}$. The collar was punched from a steel sheet of the same grade chosen for the large series production.

The result of the measurements ( $\mu \sim 1.002$ as in the untouched areas) shows that there are no changes on the magnetic permeability due to the strain hardening of the steel in the boundary zone.

\section{Series Production of the Steel for the Collars}

Like most of components of the LHC dipole structure [2], the series production of the austenitic steel for the collars is continuously monitored through graphical analysis of the data. The parameters, representative of the material performance, that are checked every coil ( $\sim 2$ tons), are: Yield Strength (Fig. 3), Tensile Strength, Elongation, Hardness, while grain size and inclusions are checked once every melt ( $\sim 40$ tons). For quality checks, the decision taken was to use the Quality assurance Plan proposed by Nippon Steel Corporation (NSC) with some small modification to the Technical Specification issued by CERN to adapt it to Japanese standards. All metallurgical and mechanical properties are measured by NSC in the frame of their Inspection and Test plan [3]. 


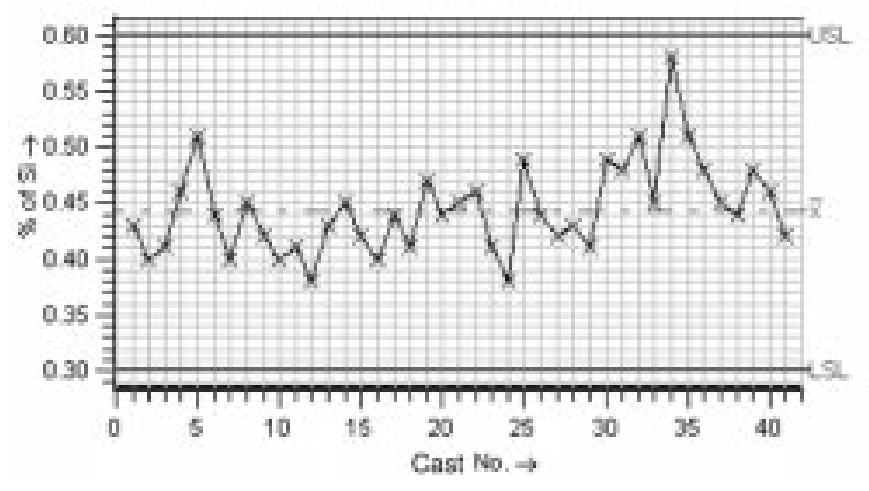

Fig. 4. Percentage of Silicon; LSL and USL are respectively the lower and the upper specification limit.

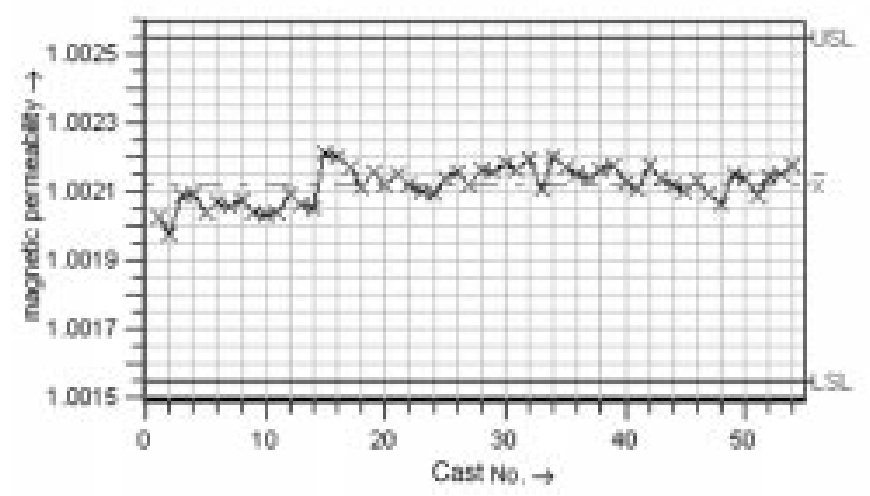

Fig. 5. Magnetic permeability at $4.2 \mathrm{~K}$ and at $1 \mathrm{~T}$, in function of the sequence of the casts. LSL and USL are respectively the lower and the upper specification limit.

CERN measures only the magnetic permeability and thermal contraction for every melt.

The parameter representative of the cast analysis, checked every cast, is the chemical percentage in weight of $\mathrm{C}, \mathrm{Si}$ (Fig. 4.), $\mathrm{Mn}, \mathrm{P}, \mathrm{S}, \mathrm{Ni}, \mathrm{Cr}, \mathrm{Mo}$ and N.

Plotting all these data with their specification limits, we can monitor the series production, and by comparison of related parameters we can identify possible changes in the process of production.

Fig. 5 shows that the first $19 \%$ (about 2000 tons) of the production is extremely stable melt by melt. The most useful parameter to monitor the production is the magnetic permeability (see Fig. 5) since it is influenced by the chemical composition, the production process and the mechanical and thermal treatments of the steel. In particular at low magnetic field (before the

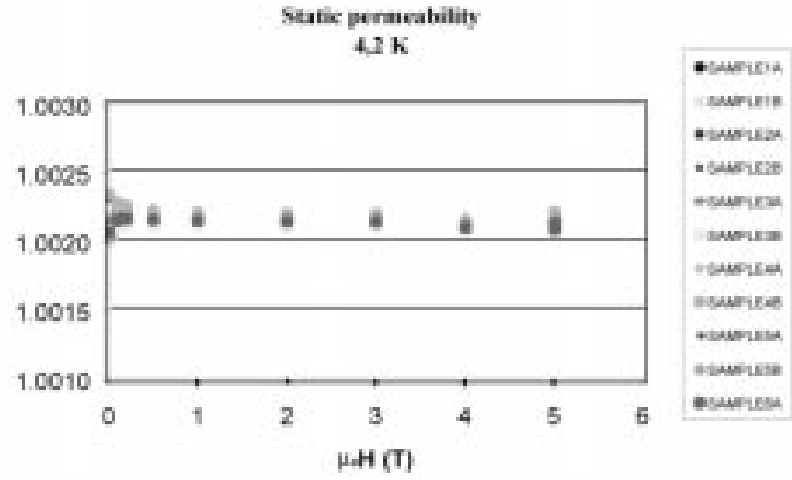

Fig. 6. Magnetic permeability, measured on different samples at different applied magnetic field and at $4.2 \mathrm{~K}$. Each sample number represent a melt; the letters A and B represent two measurements performed, respectively, in perpendicular and parallel direction. The process parameters could be different from melt to melt in order to optimize the production.

saturation), this parameter is very sensitive to changes in composition or process.

\section{CONCLUSIONS}

We pre-selected and measured the main characteristics of five grades of steel. After a competitive call for tenders the series production was launched with a precise monitoring of the main steel production parameters in close collaboration with the two Japanese producers involved (Nippon Steel Corporation and Kawasaki Steel Corporation).

\section{ACKNOWLEDGMENT}

The authors wish to acknowledge all the steel producers mentioned in this paper for their collaboration, help and their deep and genuine interest in the LHC project.

\section{REFERENCES}

[1] P. Fessia, D. Perini, R. Vuillermet, and C. Wyss, "Comparative study of different designs of the mechanical structure for the LHC main dipoles," LHC Report, to be published.

[2] P. Fessia, C. Lanza, D. Perini, and T. Verbeeck, "First experience in the mass production of components for the LHC dipoles," MT-17 Conf..

[3] Specification of Nonmagnetic Steels for Superconducting Magnet. High-Strength Nonmagnetic Steels YUS130S: Nippon Steel Corporation, October 1999.

[4] Quality Manual for Stainless Steel Sheets \& Strip: Hikari Works, Nippon Steel Corporation.

[5] "Characteristics of high manganese steel strips for the nonmagnetic collars and core voids of the LHC dipole magnets," Internal report from Kawasaki Steel Corporation, Sept. 1999. 